\title{
Géneros y Generaciones: Conducta Reproductiva de los \\ Mayas de Yucatán, México
}

\author{
Genders and Generations: \\ Behaviour of the Mayans from \\ Yucatán, México
}

Judith Ortega Canto ${ }^{1}$

${ }^{1}$ Directora del Centro de Investigaciones Regionales Dr. Hideyo Noguchi de la Universidad Autónoma de Yucatán, México. ocanto@tunku.uady.mx
RESUMEN El artículo describe y analiza el proceso de transformación de las representaciones sociales respecto a la salud/enfermedad/atención de procesos de embarazo-partopuerperio, a través de tres generaciones de parejas y la condición de género. Es a partir del papel que juega la ideología biomédica representada en las clínicas de campo de la seguridad social, y las relaciones que operan entre hombres y mujeres, que es posible distinguir los elementos protectivos y curativos, así como los elementos de tensión existentes. El trabajo muestra cómo juegan los géneros a través de tres generaciones en términos de colaboración mutua, su demanda y evaluación a la atención recibida por las parteras o a los servicios de atención alópatas, y el efecto de la medicalización sobre hombres y mujeres de la tercera generación.

PALABRAS CLAVE Identificación Social; Proceso Salud-Enfermedad; Reproducción; Efecto de Cohorte; Identidad de Género.

ABSTRACT The article describes and analyzes the process of transformation of the social representations about to the health/illness/attention processes pregnancy-childbirth-puerperium, through three generations of couples and the condition of gender. It's from the role that plays the biomedical ideology represented in the clinics of the social security, and the relations that operate between men and women, that is possible to distinguish the protective elements and curative, as well as the elements of existing stress. The work shows how play the genders through three generations in terms of mutual contribution, their demand and evaluation to the attention received by the obstetricians or to the services of medical attention, and the effect of the medicinal on men and women of the third generation.

KEY WORDS Social Identification; Health-Disease Process; Reproduction; Cohort Effect; Gender Identity. 
En este artículo describimos y analizamos algunos aspectos del embarazo, parto y puerperio a través de las representaciones sociales que mujeres y varones de cuatro grupos domésticos yucatecos pertenecientes a tres generaciones sucesivas tienen respecto de dichos procesos. Tratamos de observar cuáles son las representaciones similares, diferentes y contradictorias que existen en ambos géneros respecto de dichos procesos y de su papel en los mismos, así como los principales cambios que se observan a través de las tres generaciones tomadas en cuenta.

El material presentado selecciona $y$ sintetiza algunos de los aspectos que hemos desarrollado en una investigación que dio lugar a mi tesis de doctorado (1), por lo cual subrayamos que sólo presentamos algunos aspectos que me interesa poner de relevancia, sobre todo respecto del papel que tienen ambos géneros en el proceso reproductivo sin ningún intento de generalización, sino estableciendo lo que realmente ocurre a nivel de una situación local y específica.

\section{EL MARCO TEÓRICO-METODOLÓGICO}

La revisión de la vasta bibliografía biomédica y antropológica que existe respecto de los procesos de salud reproductiva para Yucatán nos permitió observar el desplazamiento que se hace del papel masculino, de tal manera que los hombres casi no aparecen considerados como parte de dichos procesos. En la mayoría de los estudios, la masculinidad es reducida a factor de riesgo para la salud de la mujer, en la medida que la misma se ejerce a través de un "...modelo hegemónico de masculinidad visto como un esquema culturalmente construido donde se presenta al varón como esencialmente dominante y que sirve para discriminar y subordinar a la mujer y a otros hombres que no se adaptan a este modelo" (2).

En México, esta orientación se observa en las investigaciones realizadas en diversas partes del país, en particular en Veracruz (3) y en Chiapas (4), estados en los que -al igual que en Yucatán- la población nativa tiene una notoria presencia en términos demográficos y sociales. Otra característica de la mayoría de estos estudios es el dominio de una mirada fragmentada respecto de cada etapa del proceso reproductivo, así como un tratamiento que focaliza lo biológico o lo sociocultural cuando estos factores aparecen integrados en el proceso real dentro del cual operan.

En nuestra investigación nos planteamos una serie de interrogantes referidas a diversos aspectos y especialmente al papel de los géneros, que tratamos de contestar a través de la información obtenida en comunidades rurales del municipio de Kaal-káaj (seudónimo), el cual es representativo desde el punto de vista demográfico, socioeconómico, político y cultural de nueve municipios henequenero-pesqueros.

Nuestro marco teórico parte de considerar los procesos de salud/enfermedad/atención como estructuras de significado que implica el desarrollo y uso de representaciones sociales por parte de los actores involucrados en dichos procesos. Desde esta perspectiva utilizamos conceptos y propuestas que desde fines de la década de los '30 desarrollaron para México en general y para Yucatán en particular, antropólogos nacionales y extranjeros como Benedict, Foster, Comas y especialmente Redfield y Park (a) $(6,7)$. Así como también utilizamos el concepto de representación colectiva diseñado por Durkheim a fines del siglo XIX y principios del siglo XX (8), especialmente a través de la reelaboración realizada por Jodelet (9).

Junto con estos conceptos utilizamos la metodología del "punto de vista del actor" (10) como aproximación teórico-metodológica que no solo diferencia el enfoque antropológico del biomédico sino que sobre todo otorga voz a los diferentes actores sociales que participan en los procesos de salud/enfermedad/atención (PSEA). Además partimos del supuesto metodológico de que estos procesos, así como las representaciones sociales desarrolladas respecto de los mismos, se caracterizan por el cambio y no por la inmovilidad. Y porque expresan las relaciones sociales que se establecen entre los diferentes actores sociales involucrados en dichos procesos; relaciones que implican diferentes tipos de transacciones especialmente en términos de hegemonía/subalternidad (10).

Las diferentes formas de atención de los padecimientos que operan en el contexto estudiado, especialmente las biomédicas y las 
correspondientes a la medicina tradicional, tienen notorias desigualdades en términos de reconocimiento, prestigio, vinculación y legitimación por el Estado, que se expresan a través de las relaciones de hegemonía/subalternidad que establecen entre sí y que posibilita la hegemonía de la biomedicina respecto del conjunto de las otras formas de atención, incluidas las de la medicina tradicional (11).

Los conceptos que más interesa acotar en función de este trabajo son los que tienen que ver con la perspectiva de género, ya que refieren al núcleo de nuestra investigación sobre salud reproductiva. De acuerdo con Cardaci el enfoque de género ha "permitido ampliar el estudio de la salud de hombres y mujeres más allá de los territorios tradicionales, esto es, la reproducción humana y la gineco-obstetricia, y constituye, además, una de las vías a través de las cuales es posible introducir las aproximaciones teórico-metodológicas de las ciencias sociales al campo de la salud, enriqueciendo aquellas explicaciones sobre morbi-mortalidad que no se sustentan exclusivamente en el nivel biológico sino que otorgan un papel central a los factores socioculturales y psicológicos". Cuando los datos en salud se reducen a su desagregación por sexo, están atendiendo a una pertenencia biológica, lo que "conduce a una enorme confusión semántica y a una disminución de la capacidad analítica de la categoría género, así como a una refuncionalización de los postulados de aquellas organizaciones que proponen verdaderos cambios en las políticas de salud, particularmente las referidas a la búsqueda de una mayor equidad" (12).

Género constituye "una construcción social sistemática de lo que se asume como lo 'masculino' y lo 'femenino'" (13); es una interpretación sociocultural de ser mujer o de ser hombre que cruza toda la vida. Que una persona nazca como mujer o como hombre, Ileva a que la sociedad determine cómo debe sentir, pensar, qué puede expresar o qué no (14). Desde una perspectiva antropológica, Lagarde (15) considera que todas las culturas elaboran cosmovisiones sobre los géneros y, en ese sentido, cada sociedad, cada grupo y cada sujeto manejan una determinada concepción de género, basada en la de su propia cultura. Dichas cosmovisiones además de contener ideas, prejuicios, valores, interpretaciones, normas, deberes y prohibiciones sobre la vida de las mujeres y los hombres, se caracterizan por ser marcadamente etnocentristas. Cada sujeto aprende a identificarse con la cosmovisión de género de su propia sociedad, y frecuentemente la considera como norma universal. Por lo tanto las concepciones sobre el género constituyen parte de la identidad de cada grupo y de cada sujeto.

A partir de estos y otros presupuestos trabajamos con ambos géneros y no solo con uno de ellos, dado que consideramos que los géneros se definen a través de diversos procesos y especialmente a través de las relaciones que operan entre los mismos.

Nuestro trabajo partió de una primera aproximación estadística, estudiando una muestra de 180 familias, que permitió caracterizar sociodemográficamente a los actores sociales involucrados, así como establecer el patrón de reproducción biológica de los grupos familiares. Pero la mayoría de la información que vamos a presentar corresponde al estudio cualitativo realizado a miembros de cuatro grupos domésticos pertenecientes a tres generaciones distintas, así como también a material obtenido de entrevistas realizadas a personal de salud biomédico y a curadores tradicionales.

Las entrevistas a los miembros de los grupos domésticos se realizaron con veintiún informantes claves, nueve hombres y doce mujeres pertenecientes a cuatro grupos familiares. Inicialmente eran doce mujeres y doce varones, pero dos de ellos murieron y otro abandonó a su esposa durante el lapso del trabajo de campo.

En función de características económicas y socioculturales se establecieron cuatro tipos de grupos domésticos, y en cada uno de estos grupos se entrevistaron a tres parejas relacionadas entre sí en términos generacionales y a través de la línea materna. En términos sintéticos se presentan a continuación algunas de las principales características demográficas y socioeconómicas de estos informantes. La edad de las mujeres de la primera generación de los cuatro grupos familiares oscila entre 55 y 80 años; ellas se dedican a las labores domésticas y una era experta en la elaboración de productos medicinales etnobotánicos. Dos de las mujeres eran analfabetas y dos tenían primaria incompleta. Sus viviendas son de paja y bajareque y consistían en dos cuartos 
pequeños, sin conexión de agua dentro de la vivienda y por tanto sin servicios sanitarios. Sus esposos tienen entre 60 y 85 años de edad y se dedican al cultivo de la milpa y el henequén. Todos sabían leer y escribir.

Las cuatro mujeres de segunda generación tienen entre 36 y 54 años de edad y también se dedican a las labores domésticas, ayudando al sustento de la familia con actividades comerciales que implican la elaboración de alimentos caseros (tamales, dulces); contaban con estudios de primaria incompleta. Sus compañeros tenían entre 38 y 56 años de edad y se dedicaban a las labores agrícolas; otros se empleaban eventualmente como taxistas o albañiles; uno de ellos cazaba para complementar la alimentación familiar o para ayudarse con la venta de su producto. Habían cursado algunos años de enseñanza primaria. Las viviendas combinaban la estructura tradicional con alguna habitación hecha con paneles dado que con ellos todavía viven algunos de los hijos. No contaban con servicios sanitarios mínimos, ni red intradomiciliaria de agua potable.

Las mujeres de la tercera generación tienen entre los 15 y 35 años de edad y contaban con la primaria completa, e inclusive una de ellas había realizado estudios secretariales. Estaban dedicadas a las labores domésticas y una de ellas atendía un pequeño comercio de abarrotes de su propiedad. Los esposos tienen entre 19 y 35 años de edad; uno era técnico en topografía, otro trabajaba de intendente en oficinas municipales, mientras el tercero era pescador y agricultor, y el último agricultor. Uno de ellos había cursado estudios técnicos, otro contaba con la secundaria completa, otro la primaria incompleta, y el pescador sólo sabía leer y escribir. Las viviendas se caracterizaron por estar construidas con materiales no perecederos; algunas de ellas mantenían una mezcla de ambos estilos combinando una habitación al estilo tradicional con algún cuarto al estilo urbano.

Podemos concluir que todos los grupos domésticos se encontraban en condiciones de pobreza aunque con variaciones importantes. $Y$ así uno de ellos vive en condiciones de pobreza extrema asociada al grave alcoholismo del jefe de familia, mientras otro grupo vive en condiciones superiores debido a que está compuesto por varias personas que reciben ingresos a partir de sus respectivos trabajos. No obstante todos los grupos viven en situación de pobreza, lo cual caracteriza el área donde viven estas familias, como veremos más adelante.

Previamente al trabajo de campo se realizó un listado de los principales temas y subtemas que caracterizan el proceso reproductivo, y especialmente respecto de embarazo, parto y puerperio, lo cual permitió diseñar guiones de entrevistas abiertas semi-estructuradas, que fueron aplicadas a nuestros informantes, los cuales fueron entrevistados en profundidad entre cuatro y cinco veces cada uno. Las principales temáticas sobre las cuales se obtuvo información cualitativa fueron criterios de virginidad, menarca, menstruación, regla, enamoramiento, cortejo, relaciones sexuales, anticoncepción, aborto, embarazo, parto, puerperio, menopausia y utilización y evaluación de los servicios de salud biomédicos y tradicionales.

\section{EL CONTEXTO Y EL EJE ETNOGRÁFICO}

La investigación se realizó en la exzona henequenera localizada en el norte del estado de Yucatán (México) que para 1997 concentraba el 34,2\% del total de la entidad (465.980 habitantes); contaba con una tasa de crecimiento demográfico inferior a la del resto del estado que era de 2,5\%. Del total de la población del municipio estudiado (3.250 habitantes), el 41,8\% fue registrada como económicamente activa y un $56,9 \%$ como inactiva. Los hombres representaban el $85,1 \%$ y las mujeres el $14,9 \%$ de la fuerza laboral distribuida por sexo (16). En la comunidad de Kaal-káaj se habla predominantemente el idioma castellano; la lengua maya era utilizada por las personas mayores que son bilingües, mientras que las generaciones jóvenes solo la comprenden.

La producción agrícola en el municipio se distribuye entre el cultivo del henequén, la milpa, la horticultura de bagazal y trashumante, el cultivo del cocotero y la arboricultura de solares. Aunque cada día hay más tierra por el número creciente de emigrantes, los trabajadores no cuentan con capital disponible para invertir y trabajarla. El subempleo y desempleo propician 
altas tasas migratorias, y de hecho la antigua zona henequenera funciona como una reserva de mano de obra barata, que hace de la migración pendular una alternativa recurrente de sobrevivencia. Esta zona es la principal exportadora de mano de obra a otras regiones de Yucatán, a los estados peninsulares e incluso a los Estados Unidos.

Tanto hombres como mujeres salen de sus comunidades a principios de cada semana para trabajar en ciudades como Mérida (capital de Yucatán) y Cancún (estado de Quintana Roo), y retornando a las mismas los fines de semana. Si bien inicialmente este proceso era característico del género masculino, no sólo ahora también caracteriza a las mujeres sino que en algunos casos hay una tendencia a invertir los papeles: son ahora más mujeres las que se emplean fuera de la comunidad y más los hombres que asumen los roles domésticos y el cuidado de los hijos, recurso cultural de la sobrevivencia de la comunidad maya al que se acude en distintas épocas históricas de transición económica o de persecución (17).

En Yucatán, 98 de 106 municipios se ubican en condición de inseguridad alimentaria y desnutrición, de tal manera que el $83 \%$ de los niños de 1 a 4 años que viven en la ex zona henequenera padece desnutrición aguda y crónica. El $56 \%$ de la población percibe ingresos inferiores a un salario mínimo, es decir, menos de 32,7 pesos, lo que equivale a menos de tres dólares mensuales, factor estrechamente relacionado con la pobreza extrema, y otro 35\% de la población ocupada obtiene entre uno y menos de tres salarios mínimos, es decir, entre 30 y 90 pesos, lo que equivale a entre tres y nueve dólares, que son característicos de la ocupación precaria con ingresos económicos precarios sin las mínimas condiciones laborales y prestaciones (salud, vivienda, educación). En suma, la ex zona henequenera es la más pobre de estado, y una de las más pobres de México, con $91 \%$ de su población en la categoría de "nulo a bajo poder adquisitivo" (18).

En el municipio funciona desde 1972 una clínica de campo del Instituto Mexicano del Seguro Social (IMSS) localizada en Kaal-káaj, que da servicios en el primer nivel de atención, para lo cual cuenta con un médico residente de medicina familiar, dos médicos pasantes en servicio social, una auxiliar de enfermería, un administrador, y una vez por semana, un odontólogo y un químico. Colaboran con la clínica dos parteras empíricas que residen en la comunidad. Colaboran, además, un técnico sanitario y catorce promotoras. La institución Ileva a cabo dos programas: el "normal" cuyo pago es tripartita (trabajadores, patrón y Estado) y el programa de IMSSSolidaridad pagado por medio de una cuota simbólica en especie (limpieza de la clínica, jardinería, mantenimiento de instalaciones, entre otros).

Yucatán presenta una tasa de mortalidad general de 5,2 por 1.000 habitantes, que es más elevada que la tasa a nivel nacional (4,5 por 1.000 hab.); pero mientras la tasa de mortalidad en mujeres es de 4,4 por 1.000 hab., en varones es de 5,5 por 1.000 hab. A su vez la mortalidad materna en Yucatán es de 6,32 por 10.000 nacidos vivos, mientras las tasas de mortalidad en menores de un año es notoriamente mayor para los niños $(23,96$ por 1.000) que para las niñas (19,03 por 1.000). La esperanza de vida según género es 71,90 para hombres y 76,85 para mujeres, la cual difiere de la reportada a nivel nacional $(72,43$ para los hombres y 77,36 para las mujeres) (19).

Es respecto de este contexto que entrevistamos parejas de cuatro grupos domésticos o familiares para describir y analizar procesos de embarazo, parto y puerperio.

\section{PROCESO DE EMBARAZO-PARTO-PUER- PERIO: REPRESENTACIONES DE GÉNERO Y CAMBIOS INTERGENERACIONALES}

Las doce mujeres y los nueve varones entrevistadas/os cursaban entre la segunda y séptima décadas de la vida, y especialmente los miembros de la primera y segunda generación aparecen "gastados" físicamente. Su existencia se ha caracterizado por un bajo nivel de vida, y por trabajar y haber trabajado desde pequeños hasta la actualidad en actividades que tanto a nivel doméstico como extra-hogareño implican un alto esfuerzo y desgaste físico que en el caso de varios varones -incluido uno perteneciente a la generación más joven- se ha potenciado por problemas de alcoholismo. En el caso de las mujeres el deterioro físico se expresa a través de un envejecimiento prematuro, debido también al trabajo 
desde la primera infancia, pero principalmente por el intenso trabajo en el hogar y en el solar. $Y$ así por ejemplo deben cortar y cargar en la espalda los leños que obtienen en el monte; deben preparar todos los días las tortillas, lo cual implica trabajar durante varias horas en el comal. A lo cual se agrega el lavado casi diario de la ropa, el cuidado de los hijos, el arreglo de la casa, la atención a los más ancianos, las compras. Las mujeres no descansan durante todo el día hasta que llega la hora de dormir. No obstante la mujer tiene mayor esperanza de vida, lo cual observamos a nivel estadístico para Yucatán y de nuestros grupos familiares en particular.

Recordamos que la descripción de estos procesos se basa en la observación participante, pero sobre todo en las representaciones sociales de nuestros informantes obtenidas a través de entrevistas.

\section{LOS SIGNIFICADOS DEL EMBARAZO}

Para ambos géneros el embarazo es sinónimo de cuerpos sanos, de sangre "buena", "fuerte", que se hace merecedora de la aprobación social. La "sangre" constituye un referente fundamental en la elaboración de significados relacionados con el proceso salud/enfermedad/atención desde la menarca hasta la menopausia, de tal manera que durante el embarazo es el vehículo que permite la fertilidad y posibilita la fecundación según las representaciones colectivas dominantes. Nuestros informantes de ambos géneros saben en qué momento ocurre la fecundación, y hablan del intercambio de "fluidos"; en el caso de una de las parejas de primera generación que no lograba el embarazo, fue el esposo quien recurrió a los remedios que aprendiera de su madre, para que ella los practicara y lograra embarazarse.

Un punto confuso para ambos géneros es el criterio respecto a los días fértiles identificados entre los cinco a ocho días posteriores al periodo menstrual, de ahí que proscriben las relaciones sexuales durante el periodo menstrual ante el riesgo de concebir un "engendro", lo cual es parte de un amplio contenido cultural de consejos "genéticos" desarrollados por la cultura yucateca. Las malformaciones también fueron asociadas a las relaciones sexuales y a la fecundación, cuando el hombre ha abusado de bebidas alcohólicas.

En general las mujeres, para explicar el momento de la concepción, utilizaron tanto términos biomédicos para señalar las partes del cuerpo involucradas, tales como vagina, matriz y semen, como términos populares que hacen alusión a elementos simbólicos que intervienen en la concepción de un nuevo ser: "semen" y "sangre viva".

Los síntomas de embarazo referidos por las mujeres son: vómito, náuseas, antojos, sueño, cambios físicos, aumento de peso que las hace sentirse diferentes especialmente respecto de su propia figura corporal. Ellas consideran que es una etapa que requiere "de muchos cuidados". Los movimientos intrauterinos referidos como "te jalan la barriga de un lado a otro, sientes que se estira el bebé" cuando aparecen a los cinco meses lo asocian a que el bebé será del sexo femenino; si se presentaran en etapa más temprana corresponde al sexo masculino. Casi a los nueve meses refieren "pesantez", insomnio, cansancio y dolores asociados a la proximidad del alumbramiento. El consumo de vitaminas se da al principio y al fin del embarazo, y están recomendadas tanto por el médico alópata como por las parteras empíricas. Consumen hierro o multivitamínicos.

En los días próximos al parto señalaron tener sentimientos de temor e incertidumbre respecto de ellas mismas y de si su bebé nacería bien. Para las mujeres primerizas el parto aparece como un hecho "desconocido" y asociado tanto a la vida como a la muerte, y referían no saber qué hacer, ni qué es "lo que a una le van a hacer", no existiendo diferencias generacionales al respecto.

El "buen embarazo" lo asocian al bienestar físico, a un embarazo deseado, contar con el trato esmerado del esposo, acudir a ser sobadas (b), y contar con la atención prenatal de los servicios de salud. El "mal embarazo" está asociado a dormir mucho, comer cosas agrias "que caen y dañan al bebé" y "mata la sangre de la madre"; así como a la posición transversa del bebé, al estado de enfermedad de la futura madre así como a la prematurez. También lo atribuyen a "no tener qué comer", a no desear el embarazo, y a tener un bebé de gran tamaño. Algunas informantes señalan como negativos los hábitos 
de consumo del padre, problemas familiares o con la pareja, sufrir caídas, y que el embarazo termine en aborto.

El "embarazo ideal", es referido por nuestras entrevistadas a una situación donde no existen carencias materiales, y donde dominan las relaciones afectivas.

El nacimiento prematuro y el aborto como los principales riesgos mencionados durante esta etapa son asociados al "susto" (c) ocasionado por una impresión fuerte, el consumo de tabaco o alcohol por parte del padre, y a los "deseos" (alimenticios) de la embarazada no cumplidos por parte del esposo o demás familiares. Otros peligros asociados a la muerte del bebé fueron: el circular de cordón, la estrechez de la madre que solo se resuelve por cesárea, y de ahí la importancia de contar con el servicio de la clínica del IMSS según algunos informantes. También mencionaron el retraso en el nacimiento, convulsiones en la madre y las infecciones del bebé. Consideran peligrosas para la vida de la madre a las hemorragias y a la retención de la placenta.

Ellas describieron acciones de colaboración de sus esposos durante el embarazo como ayudarlas en tareas "pesadas", Ilevarlas a pasear; así como acompañarlas para ser atendidas por la sobadora en el caso de la primera generación y algunas mujeres de la segunda; y al médico de la clínica del IMSS en el caso de la tercera generación.

La atención biomédica es descrita como aquel momento en el que les miden el volumen del abdomen, les toman la presión arterial, y les proveen de vitaminas. Una queja frecuente respecto a la atención alópata fue que no se les permitiera a los esposos estar presentes a la hora del examen prenatal y a la hora del nacimiento de los hijos. En contraste, describen a la partera como defensora de la presencia indispensable de los esposos; de su capacidad para dotar de bienestar inmediato ante su destreza para tocar y sobar, informar del bebé, acomodarlo si es necesario y hacer las recomendaciones respecto a la vida sexual, así como rezos adecuados, posiciones para aliviar el cansancio corporal, alimentación e indicaciones respecto a la magnitud de esfuerzos.

El significado que los hombres otorgan al embarazo va ligado a la obligación social masculina de vigilar que la mujer y el futuro bebé lleguen vivos y sanos, y el sentimiento positivo que les otorga la paternidad. Consideran que deben cumplir los "deseos", proveer de tranquilidad, de ayuda doméstica y mejor alimentación a sus mujeres, es decir realizar todo aquello que sea necesario para evitar complicaciones como el nacimiento prematuro y el aborto.

Entre los varones de las dos primeras generaciones, se da un mayor manejo de representaciones centradas en los cambios afectivos femeninos, más que en los corporales. Al privilegiar el bienestar afectivo, su atención se enfoca a los estados de ánimo, de humor, de sueño, de cansancio. Los cambios corporales fueron percibidos en la medida que motivaron alguna demanda por parte de ellas: manchas, hinchazón de pies, flujos. Acompañar a la mujer al control prenatal biomédico o solicitar a la sobadora forman parte de llevar adecuadamente el embarazo. El buen embarazo es equiparable a un embarazo ideal.

Los varones de las tres generaciones coinciden en sus representaciones respecto de los cambios en el cuerpo de sus esposas durante el embarazo. No solo no les incomodó, sino que se sentían atraídos por ellas, las seguían deseando, sentían que las querían más. Siempre los embarazos representaron motivo de orgullo masculino. No refirieron preferencia por el sexo del futuro recién nacido. Una de las descripciones masculinas ponen de manifiesto esta representación social: "las mujeres se ponen más guapas, les crecen los pechos y, a veces, hasta están más alegres. En los últimos dos o tres meses se aíslan, no quieren que las toquen, tienen miedo o temor, están tristes, ojerosas, se les hunden los ojos, se manchan más la cara".

En cuanto a las relaciones sexuales, la actitud estuvo relacionada con la calidad de la relación conyugal. Los sentimientos afectivos y el deseo sexual afectaron diferencialmente a ambos géneros; fueron las mujeres que se distanciaban en las últimas semanas debido a su cansancio, o a que las parteras les recomendaban no tener relaciones coitales en el último trimestre.

Los varones de la tercera generación jugaron un papel determinante en la toma de decisiones respecto del embarazo y del parto. Más apegados a la opinión biomédica, prohibieron de manera relativa o absoluta, que las mujeres acudieran a ser sobadas. En una de las parejas, el varón impuso su punto de vista; existía el 
antecedente de que sus padres y demás familiares no aceptaban su esposa lo que ocasionó períodos de difícil convivencia para esta pareja. Cuando ella se embarazó antes del tiempo indicado por el médico alópata, él expresó enojo y reclamo generándole a ella un incremento de la tensión emocional existente, elemento que visualizado en el tiempo puede fungir como explicativo del cuadro de preclampsia sufrido por esta mujer de tercera generación en su segundo embarazo. Cabe señalar que tres de las cuatro esposas de este grupo generacional resolvieron sus partos por cesárea.

\section{LA CRECIENTE MEDICALIZACIÓN DEL PARTO}

El momento del parto es probablemente el que mejor retrata la alianza entre los géneros, así como la pérdida de las funciones del varón. Según una de nuestras informantes de la primera generación, al momento del parto su esposo no se encontraba debido a que estaba trabajando en una finca vecina, por lo cual, fue su padre -cortador de henequén en una hacienda-, quien se hizo cargo de las actividades correspondientes al patrón cultural de comportamiento masculino: "cuando no lo aguanté desperté a mi papá, prendió la candela y puso agua (a hervir) y dijo: 'tienes que hacer todo lo posible por tener a tu nené', me sobó y se puso a explicarme. Me acostó, cuatro horas después (dos de la mañana) no había pasado nada, mi cuñada me dijo que no me sentara; sentí un dolor muy fuerte... que no podía ser (posible)... me levanté, me agarrré de una soga (cuerda que pendía del techo) y me dijeron: 'no saques tu fuerza por arriba sino para abajo...' y mi cuñada sostuvo mi peso (deteniéndola del talle por detrás), no dejó que me acostara, porque si te acuestas vas a matar al nené". "El (papá) viene y acerca una silla y la pone debajo de la hamaca (donde se hace el parto) y me dice: no tengas vergüenza, soy tu papá, además, aunque tu marido lo debe de hacer, esto que tienes que hacer es peligroso, te puedes morir tú o el nené'". El padre la sostenía por la espalda según indicaciones de la partera, sobre todo en el momento del período expulsivo, para facilitarle el acto de pujar. La comadrona recibía al bebé, le sacaba las flemas y cortaba el cordón. Una vez obtenida la placenta, su padre fue el encargado de desecharla bajo criterios muy específicos: "primero la pone en una tela vieja, la envuelve y la entierra; mi papá decía... 'no me gusta que un pedazo de la carne de mis hijas se desperdicie, que lo jalen los gatos o los perros...' le ponía una cruz con sal, es pecado si se deja que se la coman los animales... es un pedazo de carne de uno, por eso se entierra".

Dicha experiencia se correlaciona con lo vivido por esta misma mujer en uno de sus últimos partos, que al complicarse fue atendido en una clínica rural del IMSS. Ella presenció cómo su placenta fue devorada por unos perros, escena que le ocasionó fuerte tensión emocional debido a la representación colectiva que le otorga a la placenta un significado especial, dado que es el "compañero del bebé" y también continuidad del cuerpo. Este suceso repercutió, según nuestra informante, en su estado emocional por varios días, entorpeciendo su desempeño materno.

Las experiencias de nuestras entrevistadas pusieron de manifiesto la complejidad e involucración de los varones en la atención del parto, lo que ha llevado a que las parteras indiquen la participación masculina, en primer lugar el esposo y en segundo el padre, antes que la de otros actores sociales. Una de las mujeres señala que: “En todos los partos atendidos por la partera estuvo mi marido presente; mi marido me ayudaba, al principio sentía vergüenza porque me viera; luego venían los dolores, él me agarraba de la espalda y me colgaba de su cuello para hacer fuerza, me sentía apoyada, acompañada, tranquila, segura... después, él iba a enterrar la placenta, él siempre estaba pendiente de lo que necesitara". En esta pareja, el esposo fungió como partero del segundo de los ocho alumbramientos de su esposa. Ella misma aclara que de sus ocho partos, los cuatro últimos fueron atendidos en el IMSS calificando como buena la atención recibida, pero, "lo único que no se podía era que mi marido estuviera en el momento que nacieron mis hijos. En mis cuatro últimos partos mi esposo no pudo estar presente, me sentí diferente, me sentía sola y triste... él se quedaba afuera a esperar por si necesitaba algo; algunas veces tuvo que pasar la noche (en la clínica), dormía en el suelo".

En la experiencia de los esposos más jóvenes sobresale la idea de que es mejor que no 
les sea permitido presenciar el parto, pues resulta una experiencia que prefieren evitar. Sin embargo, junto a este discurso, encontramos la desesperación experimentada por uno de ellos cuando su presencia fue cancelada generándole dudas, y replanteándose si no es mejor el parto tal como lo recomienda la partera.

El parto normal es lo aceptado entre los géneros y las tres generaciones femeninas y masculinas, como lo adecuado, y por eso, la cesárea no tiene la connotación de parto o la tiene en términos de "mal parto". El cuerpo cortado o mutilado por la operación cesárea es cuestionado ante su mal funcionamiento o atribuido al mal desempeño de la mujer en cuanto a los cuidados que debió llevar a cabo. Los varones cuyas esposas vivieron la cesárea a excepción del esposo de una madre adolescente, refieren lo frustrante que para ellas resultó dicha experiencia, porque no pudieron demostrar que su cuerpo podía enfrentar "una de las verdades de la maternidad". Para ambos géneros, la mujer intervenida quirúrgicamente, es decir, una mujer cortada vale menos dado que tiene "cuerpo de hombre". Esta representación respecto a la cesárea cuestiona la práctica médica cuya tendencia es a decidir con mayor frecuencia tal intervención colocando entre paréntesis los efectos farmacológicos y psicológicos negativos de tal intervención (20). Debemos subrayar que en el contexto estudiado la cesárea tiende a imponerse.

En la medida que el parto ha sido una experiencia compartida entre géneros, observamos que los varones entrevistados pueden describir con fluidez los signos correspondientes a los diferentes momentos del parto, lo cual se expresa en las siguientes experiencias. Los hombres de primera y segunda generaciones identifican los signos y síntomas iniciales: el paso del tapón mucoso seguido del inicio de los dolores, la ruptura de la bolsa ("pasan líquido"); describen que sus esposas se ponen nerviosas por lo que les está pasando, y ellos sienten miedo y pena por lo que les pueda pasar a ellas.

Los criterios para ambos géneros sobre los condicionantes de buen o mal parto están asociados a haber contado con una buena alimentación, tranquilidad, buen crecimiento y posición del bebé. Uno de los entrevistados de primera generación informó que su nieta -la adolescente ya mencionada-, al tener un "susto" empezó a "pasar líquido", su esposa dijo entonces "que el niño tenía que nacer". En el IMSS les anunciaron que el parto no sería normal, y mencionaron lo importante de la calidad de atención, ya que a la parturienta "le duele y vuelve a meter al niño, por lo que hay que darles fuerzas, y no solo regañarla". La mujer maltratada o "golpeada por el esposo" podría ser causa de un mal parto ya que puede tornarla "cobarde" o "no desear al bebé" dice uno de los entrevistados.

De las experiencias vividas con las parteras, los varones de mayor edad mencionan sentimientos de emoción, sentirse útiles y adquirir una responsabilidad: “...mi hijo no salía y sentí la responsabilidad de ayudarla, tenía que darle fuerzas y le dije que se sentara así... recta y me puse atrás de ella, le dije que se colgara de mi cuello, que yo la ayudaría y así lo hizo... sentí que casi me arranca la cabeza... pero salió el niño. Me sentí útil, sentí que le salvé de una cortada, una picada, una operada, me sentí bien. Ahora no se me olvida, sentí que algo ya aprendí y puedo ayudar a mi hijo en su hora". Ellos refieren también que la partera "si acepta recibir al bebé, le lava la ropa del bebé y de la mamá después de que nace, aunque mi mamá y mi suegra también se han encargado de eso. Le corta el ombligo con tijera recién hervida en agua, lo tuesta para que seque rápido y arregla donde salió el bebé. Luego me da la placenta para que la entierre profundo y no se la coman los perros".

Pero según el padre adolescente: "me dicen que antes lo señores ayudaban a las comadronas, creo que es difícil, a mí no me gustaría, creo que actualmente los hombres tienen ventajas, además, los médicos tienen los adelantos para atender a las mujeres".

Los entrevistados saben de la angustia, el dolor y el riesgo de muerte que enfrentan las mujeres durante el parto, y expresan la necesidad de ser útiles en tan importante momento. Empatía y participación en una etapa que compete a ambos géneros, se expresan en el contenido de representaciones sociales de los varones respecto al proceso reproductivo femenino (d). En términos comparados los varones con mayor experiencia de vida urbana y mayor nivel de escolaridad evidencian una menor necesidad de participar en el proceso reproductivo, y así son los varones de 
primera y segunda generación pertenecientes a los grupos domésticos más tradicionales quienes manejan un sistema de representaciones y de prácticas que incluyen más elementos culturales, incluidos los que refieren a la participación masculina.

La decisión de quién atenderá el parto queda a cargo de las mujeres, quienes definen en qué momento solicitan los servicios de las curadoras en el proceso del embarazo y al momento del parto, sin dejar de considerar que algunas de ellas deciden según el deseo masculino. En su mayoría son apoyadas por los esposos. Los varones de tercera generación que nunca han presenciado un parto, no son capaces de describir lo que la mujer vive comparados con los que han sido partícipes de tal evento. La participación de los varones es parte de la tradición de la cultura maya/yucateca, de tal manera que las cuidaban, Ilamaban a la partera, traían yerbas para espantar los vientos, ayudaban, consolaban y se sumaban al aporte de energía femenina al momento del trabajo de parto. Los varones de primera y segunda generaciones participaron de los partos de sus esposas.

De los varones de la tercera generación, solamente uno de ellos tuvo esta iniciativa; su pertenencia a grupos domésticos más tradicionales y su reconocimiento del papel de las curadoras populares favorecieron esta actitud. Los jóvenes esposos no partícipes rechazan la presencia de la partera; aunque sin embargo, a la hora del parto se extrañan de que el personal de salud no les permita estar presentes, y evocan entonces el proceso a cargo de la partera. Su preferencia por el parto atendido por médicos está asociada a que cuentan con instrumental, medicamentos, sangre, sueros y la capacidad para practicar la cesárea. Las parejas de tercera generación consideran que las sobadoras y parteras corresponden a un tiempo en que no había médicos, por lo cual su presencia ya no tiene razón de ser (21).

Es en el parto atendido por partera donde se materializa una fuerte colaboración entre los géneros y la curadora, seguido del papel que juega la red de relaciones en la que las suegras, madres, abuelas y demás familiares tienen algún tipo de participación. Las velas, el agua caliente, las imágenes religiosas, todo en un lugar cerrado para evitar que se filtre el aire $y$ pueda dañar a la mujer que se encuentra pariendo en la hamaca. El hombre aparece como el ayudante fundamental para la partera, y para la parturienta constituye la contraparte de su propio cuerpo. La partera entrevistada describió la variedad de estados de ánimo de los miembros de ambos géneros, señalando que hay hombres que colaboran, otros que rezan o que Iloran. El escenario del parto observado por nosotras es el lugar que permite cuestionar ciertas generalizaciones sobre el papel de los géneros, ya que evidencia el ejercicio de actividades y actitudes complementarias en mujeres y varones.

\section{EL PUERPERIO Y SUS ACTORES}

Es en la etapa del puerperio, que las tres generaciones retoman la valía de las recomendaciones de antaño, siendo una etapa en la que la medicina popular es el saber que guía la construcción de las representaciones.

Los informantes de ambos géneros y de las tres generaciones expresaron consenso respecto de la mayoría de los aspectos del puerperio. Para las mujeres la representación social central se organiza respecto de la "herida" o "Ilaga" que queda en la pared de la matriz. Aunque esta representación también fue referida por los maridos, la idea central en ellos refiere al largo período de abstinencia sexual que deben cumplir; la curadora pide "no tocarlas" en función de los patrones culturales yucatecos, por lo que ven afectada su sexualidad. Algunos mencionaron que durante este lapso recurren a las Ilamadas "particulares" que son mujeres nativas de la comunidad que acceden a tener relaciones sexuales con varones en su casa a cambio de dinero. Se les prefiere por no representar riesgo de contagio como ocurriría con las mujeres de la "zona roja" localizada fuera del municipio. Algunas de las "particulares" son casadas o viudas, y mientras que en los varones domina una actitud positiva hacia ellas, en las mujeres domina una representación negativa que no llega a la estigmatización. Algunas de nuestras entrevistadas reconocen en ellas, funciones de relevo cuando la abstinencia sexual debe ser cumplida, y en ningún momento aparece considerada como prostitución.

Los cuidados durante esta etapa están centrados al inicio en mantener el calor del cuerpo femenino, basado en la utilización de 
rituales de cura y prevención tradicionales y especialmente referidos al holok-al o "sobreparto", síndrome cultural que refiere a la semiología de la infección puerperal. Los cuidados intensivos ante el peligro de muerte de la madre y en menor medida del hijo, evidencian la valoración social que la mujer-madre tiene al interior de estos grupos familiares. Haber parido con o sin complicaciones, logrado un hijo vivo o aún fallecido no solo es valorado positivamente por la familia y la comunidad, sino que implica el uso de tratamientos para rehabilitar a sus cuerpos "debilitados" o "destrozados", utilizando sus propias palabras. Ello supone la aplicación del baño de hojas medicinales, vigorizarse con una alimentación especial, ser sobadas para reconfortar los "cuerpos desolados", y ser "amarradas" (e) a fin de que el componente óseo retorne a sus lugares anatómicos. La "Ilaga" deberá cicatrizar mediante el reposo y la abstinencia sexual, prescripción que el marido deberá respetar a pesar suyo.

Para cumplir estos patrones socioculturales, mujeres y varones tienen fuertes limitaciones estructurales básicas para cumplir con las recomendaciones a realizar durante los cuarenta o sesenta días del puerperio según las recomendaciones de los curadores populares o alópatas, por lo que solamente los realizan durante los primeros ocho días. La buena alimentación según patrones propios y biomédicos y la ayuda constante del compañero que organiza su tiempo laboral para quedarse en casa y ayudar a su esposa por una semana, es en realidad lo que logran organizar. El reposo por ejemplo, el cuidarse de los enfriamientos, entre otras, no van con sus posibilidades una vez que el esposo regresa a su labor diaria. Sin embargo, las descripciones femeninas respecto a las atenciones que las entrevistadas reciben durante la etapa puerperal denotan esmero, calidez y solidaridad por parte de los esposos. Ellos les calientan el agua para el baño, les preparan su chocolate caliente, a veces cocinan, hacen las compras, cuidan de los niños mayores, referentes que ellas describen como motivos para amar a sus esposos; aunque el tiempo que esto dura sea unos pocos días.

Las representaciones sociales organizadas en torno del puerperio gozan del consenso de las mujeres y varones de las tres generaciones.
Aun el varón de tercera generación que prohíbe la sobada durante el embarazo, en la etapa puerperal insiste en la importancia de la amarrada a los cuarenta días y la nomina la "sanada de los huesos". Tanto mujeres como varones están de acuerdo en que "los médicos no saben de ello" de manera que si la mujer padeciera un "sobreparto" debe pensarse como causales un enfriamiento, alguna impresión fuerte como los disgustos, o haber roto la abstinencia sexual.

En todos los grupos domésticos la construcción de la identidad masculina conlleva el ejercicio de la paternidad a través de apoyar afectivamente, hacerse cargo de trabajos del hogar, fungiendo como amortiguadores y protectores de la vida de sus mujeres para que éstas puedan cursar un buen embarazo, enfrentar los dolores propios del parto y transcurrir un puerperio sin el riesgo del "sobreparto". Debo subrayar que ésta no sólo es la representación social dominante sino que hemos podido observarlo en sus propias prácticas sociales.

Si bien el papel de la religión durante el embarazo y el parto promueve el rezo a determinadas vírgenes acompañados de veladoras a la hora del parto, en el puerperio pasa a un segundo plano ante la importancia que adquiere la "medicina caliente" en esta etapa, la cual refiere al uso de plantas medicinales para los baños, los brebajes, el reposo, la comida recién preparada, la habitación cerrada, entre otros que conforman un ritual que busca mantener el calor corporal y reconfortar a la puérpera. $Y$ que tienen que ver con la concepción dominante sobre la relación frío/caliente.

La etapa del puerperio guarda mayor riqueza de contenidos populares aunque se observan diferencias generacionales. Si bien el sistema cultural promueve en las tres generaciones la intensificación de los cuidados durante el puerperio, no obstante las dos primeras generaciones seguirán al pie de la letra las indicaciones de las parteras, mientras las mujeres de la tercera generación seguirán aquellas recomendaciones que no impliquen contacto con la partera.

La mortalidad materna no es una experiencia vivida en estos grupos familiares, mientras que la mortalidad infantil mantiene un promedio de dos hijos muertos por diversas causas infecciosas en tres de los cuatro grupos estudiados, lo 
cual debe leerse asociado a las condiciones materiales de vida. Si bien el proceso de embarazoparto-puerperio se caracteriza por el cuidado que los miembros del grupo familiar emplean, a partir del nacimiento, los niños y sus madres enfrentan las consecuencias de una vida precaria.

\section{SABER BIOMÉDICO Y SABER POPULAR: TRANSACCIONES COMO INTELIGENCIA SOCIAL}

Lo desarrollado hasta ahora no implica ignorar que, como lo hemos demostrado en nuestra investigación (1), existen no solo conflictos sino violencia entre los géneros, y especialmente contra la mujer, aunque según nuestros datos la mayor parte de esta violencia no es de tipo físico. Subrayamos estos aspectos porque nuestra información cuestiona lo señalado por otros trabajos que suelen generalizarse tanto para los grupos familiares de Yucatán (22) como de otras partes de México.

Según la bibliografía consultada los grupos mayas han construido un saber respecto de la salud reproductiva que orienta la conducta de hombres y mujeres para enfrentar el proceso de embarazo-parto-puerperio, incluidas situaciones de alto riesgo concentradas en la situación de la mujer y de su hijo, y que nosotros documentamos en nuestro estudio, lo cual no significa idealizar dichos saberes culturales ni ignorar sus problemas sino recuperar sus aspectos positivos. Sin embargo, este saber se ve amenazado por varios factores y especialmente por la difusión de la cultura biomédica, lo cual es observable especialmente por la paulatina desaparición de las parteras empíricas en el área henequenera desde que se instaló el IMSS en 1972. Por lo cual las comunidades ya no cuentan con el personaje encargado de aspectos decisivos del embarazo, parto y puerperio, a través de los cuales posibilitaba el mantenimiento de la cultura maya incluido el papel del varón en relación con estos procesos. No obstante debemos reconocer que las condiciones actuales de la atención del embarazo/parto/puerperio se traducen en una notable disminución de las complicaciones y mortalidad materna.
Hemorragias, distocias, circular de cordón y convulsiones que ponen en riesgo de muerte a la madre y al bebé, son contingencias temidas por mujeres y varones dada la incompetencia tecnológica de las curadoras populares. De tal manera que se reconoce la eficiencia técnica de las curadoras populares para diagnosticar un parto complicado por alguna de las causas mencionadas, pero también se reconoce la ineficacia respecto de las mismas.

Con diferencias y semejanzas por generaciones y géneros, la relación de las parejas con los servicios biomédicos de salud es fundamentalmente de tipo transaccional; se acude a dichos servicios ante la ausencia de parteras, el temor al parto complicado o en el caso de complicarse el parto atendido por la partera. Estas familias realizan una suerte de síntesis entre aspectos de la cultura popular y de la cultura biomédica que utilizan según las circunstancias específicas por las cuales atraviesan.

Si bien el sistema popular mantiene vigente su concepción del proceso de embarazoparto-puerperio a través de reconocer el papel de las parteras empíricas, son las mujeres y varones de las primeras dos generaciones quienes mantienen el uso y la transmisión de estas prácticas y significados sociales cuando se trata de familias más apegadas a la vida rural, no ocurriendo ello con familias que cada vez adoptan más un estilo de vida urbano.

El análisis de las tres generaciones permite observar cambios en las formas de percibir y atender los procesos reproductivos, y especialmente las modificaciones que se dan en la generación más joven. Así las mujeres y varones, principalmente de la tercera generación, rechazan ciertas prácticas populares cuando la migración a la ciudad les genera distancia con su comunidad, su familia y los curadores populares. La negativa de la mujer a las prácticas populares, a veces impuesta por el esposo, es vivida como expresión de un mayor status social que se ejerce -en parte-, acudiendo a los servicios biomédicos de salud, tales instituciones modernas. El mayor nivel educativo de esta generación parece también incidir en esta toma de decisiones.

Si bien la biomedicina constituye la práctica de atención preferida por la tercera generación, 
ello no implica que desaparezcan las representaciones sociales tradicionales por varias razones, entre las cuales sólo señalamos dos. Primero porque casi siempre suelen modificarse las prácticas antes que las representaciones, y segundo porque la biomedicina maneja una concepción técnica y eficientista de los cuerpos en reproducción sin integrar el concepto de proceso reproductivo femenino. Si bien tanto la cultura popular como la cultura biomédica buscan evitar las muertes materna e infantil desde visiones diferentes, lo cierto es que es bajo la hegemonía de la biomedicina que se reduce notoriamente la mortalidad y las complicaciones devenidas de las condiciones del parto/embarazo/puerperio.

Pese a esto, por lo menos una parte de las mujeres y los hombres continúan recurriendo a las escasas curadoras populares, pese a reconocer-como lo señalamos- la mayor eficacia de la práctica médica y las deficiencias del trabajo de las parteras. Pero nuestros informantes hablan también de las deficiencias del saber biomédico, ya que según ellos los médicos no saben del "pasmo", ni de los "sustos", de la importancia de los "deseos", de cómo "viene el niño", de los "vientos", del riesgo del "sobreparto", de la "medicina caliente". En síntesis, los médicos "no creen en lo que la gente cree... y no creen porque no saben". Aún en la generación más joven se reconoce el papel de las recomendaciones de sus familiares más "tradicionales", enfatizando que por venir de las personas con experiencia "deben ser siempre respetadas".

Puede decirse que las relaciones entre saberes fungen como hilos conductores para observar el proceso de transformación de las representaciones y sus significados sociales. El saber de un grupo al aprobar cambios, tiene la capacidad de definir en qué medida éstos suceden; por ejemplo, el carácter utilitario que los grupos domésticos le otorgan al uso de servicios de salud alópatas, es un ejemplo ilustrativo del carácter transaccional que observamos entre la cultura popular en salud y la cultura biomédica. Si bien las prácticas biomédicas inciden en mejorar las condiciones del proceso reproductivo, sin embargo genera pérdidas, modificaciones y discontinuidades como las que observamos especialmente en el saber de la tercera generación y en la pérdida de funciones del varón.
Desde esta perspectiva es importante considerar que la exclusión del varón que observamos en los servicios biomédicos de salud es una expresión más del proceso que está desplazando a las parteras, al mismo tiempo que fractura al sistema cultural en salud reproductiva construido por la cultura maya. Pero también es expresión de la imposición que los servicios de salud ejercen sobre las prácticas tradicionales de la población. Todo lo cual supone una importante pérdida para el cuidado de la salud de las mujeres y de sus hijos, pérdida que no solo debe ser vista desde la cultura popular sino también desde el propio discurso de los servicios de salud biomédicos ya que el discurso oficial señala la importancia de involucrar a los hombres, pese a que en la práctica los excluye por lo menos en los servicios de salud de Yucatán.

Para concluir considero que la perspectiva intergenérica e intergeneracional permite tener una visión más integral de los procesos reproductivos, que esperamos haber concretado en este trabajo. El análisis intergeneracional permitió distinguir el proceso de transformación de las representaciones sociales respecto al embarazo-parto-puerperio, distinguiendo las continuidades, discontinuidades y pérdidas asociadas a particularidades de la red de relaciones en las que estaban inmersas las mujeres y los hombres en relación a las curadoras populares y personal alópata. Asimismo pudimos observar el efecto de la biomedicina en las representaciones y prácticas de los diferentes grupos domésticos estudiados.

Considero que nuestro trabajo ha evidenciado la existencia de comportamientos de rol en términos de mujeres y de varones respecto de los procesos de salud reproductiva, y en particular ha registrado el papel activo del varón en varios de dichos procesos, que posibilitan una articulación entre los géneros y no su exclusión. Desde esta perspectiva son los servicios de salud biomédicos los que -junto con otros procesosestán excluyendo a los varones del proceso reproductivo en instancias consideradas básicas por parte de la cultura popular yucateca. Al mismo tiempo nuestro trabajo ha documentado la presencia del varón durante el proceso reproductivo como una obligación cultural que contradice lo sostenido por la mayoría de los estudios de género respecto del rol del varón, y especialmente las 
concepciones feministas que sostienen una visión unilateral y generalizante, que por lo menos en las comunidades estudiadas por nosotros no funciona en términos empíricos ni de interpretación teórica.

Desde una perspectiva salubrista, y a partir de asumir las recomendaciones que las tendencias biomédicas de punta proponen respecto de la presencia activa del varón en todo el proceso reproductivo como medio para lograr una mejor salud de la mujer y sobre todo del "producto", nos interesa rescatar no sólo la articulación de género que observamos en algunos de los principales procesos reproductivos, sino la posibilidad de que la misma sea integrada y no excluida por los servicios de salud de Yucatán.

\section{NOTAS FINALES}

a. R. Redfield y M. Park en 1940 realizaron en Dzitás, Yucatán, un estudio sobre la enfermedad y el tratamiento que contiene información sobre "concepción, embarazo y nacimiento" (5).

b. La "sobada" es una experiencia vivida por las mujeres de primera y segunda generaciones y algunas de tercera generación a partir del cuarto mes. Consiste en colocar en el suelo una cobija gruesa para acostar a la embarazada y sobarla de los pies hasta la cabeza o si ella lo prefiere, puede ser en su hamaca. El frotamiento y masaje que la partera o la sobadora aplica iniciando con la planta de los pies, piernas, muslos, espalda, abdomen, brazos, garganta y cabeza, busca reconfortar, relajar posible tensión muscular y reducir dolores musculares. Además su efecto psicoterapéutico va en relación directa con la conversación que dicha curadora sostiene respecto a malestares causados por el propio embarazo, relaciones interpersonales, el apoyo del esposo, y el posicionamiento del bebé. Este último punto se da en el momento que toca al abdomen; la curadora va delimitando la posición del bebé, la altura uterina, los movimientos y su percepción de que todo marcha bien, si percibe alguna alteración, y el tiempo aproximado para el alumbramiento. Cuando el nacimiento está próximo, la sobada se realiza cada semana o cada quince días.

c. El "susto" es un síndrome cultural que refiere a la semiología que informa de una circunstancia de vida de la embarazada con algún fenómeno natural o algún incidente inesperado que le ocasiona un fuerte impacto emocional. El "susto" fue asociado a ruptura prematura de membranas, con el desencadenamiento de aborto y con el parto prematuro. Proteger a la gestante de esta condición tiene fuertes implicaciones protectivas y preventivas de riesgos y complicaciones para la vida de la gestante y el futuro recién nacido.

d. Proceso Reproductivo Femenino (PRF) es la categoría de análisis que dinamiza la reproducción como el continuum de eventos y etapas que conforman un todo difícil de escindir; vivido y compartido entre mujeres y hombres, motivando variadas formas de interacción en cada grupo social. Esta categoría permite aprehender la relación entre factores biológicos y socioculturales de manera que las representaciones y significados sociales de las mujeres y sus parejas heterosexuales, así como demás actores fundamentales que intervienen en este proceso que inicia con la menarca y la menstruación, para seguir con el embarazo, el parto y el puerperio, y terminar con la menopausia, contempla además, las prácticas de la anticoncepción, el aborto y el infiltrado de la sexualidad. Las representaciones y prácticas durante el PRF son influidos por los cambios sociales e ideológicos que impactan a través del tiempo, las formas de entender y atender el proceso de salud-enfermedad-atención (1).

e. La "amarrada" es una sola experiencia que viven las mujeres en la etapa puerperal en manos de las parteras. Se coloca en el suelo una cobija gruesa donde acostar a la puérpera. Con trapos largos y limpios a manera de vendas, se realiza un vendaje algo apretado desde los pies hasta la cabeza, buscando que la mujer permanezca así durante varias horas, a veces todo un día si fuera posible. Esto ocurre al final de los cuarenta días de los cuidados intensivos. 


\section{REFERENCIAS BIBLIOGRÁFICAS}

1. Ortega-Canto J. Proceso reproductivo femenino: saberes, géneros y generaciones en una comunidad maya de Yucatán. [Tesis Doctoral en Ciencias Sociales]. México: El Colegio de Michoacán; 1999.

2. Keijzer B. El varón como factor de riesgo: Masculinidad, salud mental y salud reproductiva. En: Tuñon E, coordinadora. Género y salud en el sureste de México. Villa Hermosa: ECOSUR/UJAD; 1997. p. 49-70.

3. Castro R, Bronfman M. Salud, embarazo y anticoncepción en dos comunidades rurales de México: un estudio comparativo. En: Las Mujeres y la Salud. México: El Colegio de México; 1995. p. 27-68.

4. Freyermuth G. Las Mujeres de humo. Morir en Chenalhó. México: CIESAS, Porrua; 2003.

5. Redfield R, Pack M. Enfermedad y su tratamiento en Dzitás, Yucatán. Washington DC: Carnegie Institution; 1940. Publicación 523.

6. Aguirre B. Antropología Médica. México: CIESAS, Ediciones de la Casa Chata; 1986.

7. Menéndez EL. Poder, Estratificación y Salud. Análisis de las condiciones sociales y económicas de la enfermedad en Yucatán. México: INAH; 1981. p. 376-379.

8. Durkheim E. Las formas elementales de la vida religiosa (1912). México: Colofón/Premia; 1968.

9. Jodelet D. Las representaciones sociales. París: Press Universitaires de France; 1988. p. 31-61.

10. Menéndez EL. El punto de vista del actor: Homogeneidad, diferencia e historicidad. Relaciones. 1997;69:237-270.

11. Menéndez EL. Hacia una práctica médica alternativa. Hegemonía y autoatención (gestión) en salud. Cuadernos de la Casa Chata. 1983;83.

12. Cardaci D. Salud, género y programas de estudios de la mujer en México. México: PUEGUNAM, UAM; 2004. p. 12, 25, 34.
13. Castro R, Bronfman M. Teoría feminista y Sociología médica: bases para una discusión. En: La condición de la mujer en el espacio de la salud. México: El Colegio de México; 1998. p. 210.

14. Careaga G. Las relaciones entre los géneros en la salud reproductiva. Comité Promotor por una Maternidad sin Riesgos en México. [Mimeo] México: CPMSR; 1996.

15. Lagarde M. Género y feminismo. Desarrollo humano y democracia. 2 da ed. Madrid: Horas y horas; 1997. p.14, 25.

16. Instituto Nacional de Estadística, Geografía e Informática. Anuario Estadístico de Yucatán. 1997. México: INEGI; 1997.

17. Boccara M. Cultura Urbana. Periódico Por Esto! 27 de julio de 2003. Unicornio, Suplemento Científico y Cultural.

18. Peraza-Menéndez J. Condiciones de vida y desarrollo humano en Yucatán. Diagnóstico [documento]. Yucatán: CONAFOVI-Gobierno de Yucatán-COUSEY; 2001. p. 64-65.

19. Instituto Nacional de Estadística, Geografía e Informática, Secretaría de Salud, Consejo Nacional de Población. Proyecciones de población del 2000 al 2005. México: INEGI, SSA, CONAPO; 2002.

20. Good-Maust M. The Midwife or the Knife: The Discourse of Childbirth by Cesarean in Mérida, Yucatán. LATIN AMERICANIST. 1994;30(1):7-11.

21. Guemez M. De comadronas a promotoras de salud y Planificación Familiar. En: Krotz E, editor. Cambio Cultural y Resocialización en Yucatán. Tratados y Memorias de Investigación de la Unidad de Ciencias Sociales. México: Ediciones de la Universidad Autónoma de Yucatán; 1997. p. 117-147.

22. Richardson MR. Concebir, Alumbrar, Educar: Algunos aspectos de la Vida Reproductiva de las Mujeres en el Yucatán Rural. En: Ramírez L, compilador. Género y Cambio Social en Yucatán. México: Ediciones de la Universidad Autónoma de Yucatán; 1995. p. 183-234. 